\title{
Facial Analysis and Malocclusion of Children Attending a Dental School Clinic
}

\begin{abstract}
Estthelamares Lúcio da Silva Mello', Maria das Graças Duarte², Sônia Maria Soares da Silva ${ }^{3}$, Guilherme Soares Gomes da Silva ${ }^{4}$, Maria da Conceição de Barros Correia ${ }^{4}$, Leonardo Cavalcanti Bezerra dos Santos ${ }^{4}$, Marcela Silva de Vasconcelos ${ }^{4}$, Kátia Maria Gonçalves Marques ${ }^{4}$, Niedje Siqueira de Lima ${ }^{4}$ and Luciana de Barros Correia Fontes ${ }^{4 *}$
\end{abstract}

${ }^{1}$ Dentistry Student, Federal University of Pernambuco, Brazil

${ }^{2}$ Phonoaudiologist, Clinical Hospital of the Federal University of Pernambuco, Brazil

${ }^{3}$ Professor at Mauricio de Nassau University Center, Brazil

${ }^{4}$ Professor at Federal University of Pernambuco, Brazil

*Corresponding author: Luciana de Barros Correia Fontes, Department of Clinical and Preventive Dentistry, Federal University of Pernambuco, Brazil

\begin{abstract}
Objective: To characterize the face and the malocclusion type of children treated at a dental school. Materials and Methods: Retrospective analysis of clinical data with orofacial measurements of 103 children of 6 to 9 years of age with mixed dentition, who received the first care between 2016 and 2017. The data were obtained from the anthropometric measurements, using a caliper and digital technology. This work is linked to an extension project. The research project was approved by the Ethics Committee on Human Research of the Federal University of Pernambuco, Recife, northeast of Brazil, under protocol number 77741417.0.0000.5208. Statistical treatment was performed, with a margin of error of $5 \%$.

Results: Most records occurred in male children (57.3\%), mean age $7 \pm 0.9$ years and brachyfacial type (40.8\%), with significant differences according to gender $(\mathrm{p}<0.05)$. The mesofacial type was more frequent in males while the brachyfacial type was found in females. Regarding the distribution of malocclusions, there was a higher percentage for Angle Class I (40.8\%) and for unilateral posterior crossbite $(29.1 \%)$. Gender significant differences $(\mathrm{p}<0.05)$ occurred between lower third of the face height, dolichofacial type and class II malocclusion (together), all higher in males than in females. Conclusion: The most frequent type of face in children with mixed dentition was the brachyfacial and Angle Class I malocclusion. Morphological evaluation can be used in place of digital analysis because it has equivalence to it; despite different approaches to the measures.
\end{abstract}

Keywords: Face; Image processing; Computer-assisted; Child

\section{Introduction}

Dental alignment predominated with the emphasis of orthodontic treatment until the mid-twentieth century, when facial balance began to be considered as an important guiding feature of the quality of the results obtained. Currently, the evaluation of the patient's facial and oral soft tissues is the starting point for understanding the disposition of the facial bones and establishing the diagnosis and treatment plan. Dental elements and occlusion are not evaluated in isolation, but soft tissues and how they relate to teeth and skeleton. Therefore, the diagnosis involves assessing the behavior of the facial skeleton through clinical analysis of the face and thereby planning an orthodontic treatment that provides the patient with a pleasant aesthetic and functional occlusion [1-3].

The analysis of facial proportions does not only involve aesthetic values. The human face consists of muscle and bone structures, which vary according to the individual's facial typology. Each type or facial pattern has its own characteristics, which can be observed in the orofacial musculature, shape of the craniofacial structure configuration, dental arch shape and occlusion. The characteristics of each facial type can directly influence the functions of chewing, swallowing, voice, breathing and speech [4]. In the brachyfacial 
type, there is a greater growth in the horizontal direction, in the meso-facial type the horizontal and vertical facial growth vectors are balanced and in the dolichofacial type there is a predominance of vertical growth $[4,5]$.

Several methods for performing facial analysis are described in the literature. There are studies that recommend the analysis of soft tissues of the face through lateral cephalograms, that is, a cephalometric analysis, while other studies recommend the anthropometric evaluation of its morphology, using a caliper (quantitative evaluation methods). There are also more subjective methods, which include a visual assessment only through the use of photographs and computerized morphological evaluations of the face, especially facial proportions in frontal norm [4-8].

It is recognized that facial analysis should also be performed in children, in deciduous and mixed dentures, because the infant's facial pattern tends to be maintained with facial growth and development due to the great genetic influence [9]. In addition, there is a relationship between facial and occlusal characteristics $[10,11]$. Despite what was previously reported, the analysis of children's facial proportions is scarce in the literature, which justified the development of the present study. The objective of this study is to characterize the face of children treated at a dental school and to verify if there is a relationship between facial type and malocclusion presented by these children.

\section{Material and Methods}

Retrospective study, based on secondary data related to Orofacial Motricity assessments, linked to the extension project "Smiling at Family", developed at the Department of Clinical and Preventive Dentistry of the Federal University of Pernambuco, on the city of Recife campus, northeast of Brazil. For a total of 103 records evaluated, the database included information on children assisted at the dental school clinic, aged between six and nine years, of both genders and attended between 2016 and 2017.

The sample included data from children aged six to nine years, in the mixed dentition phase, with erupted first permanent molars, presenting some type of malocclusion and who attended for care at the full-time children's clinic. No data were recorded from children with neurological impairment or birth defects; characteristics that could influence in the context of communication or aesthetic and functional impact on the oral region, in addition to the condition of malocclusion.

In order to develop this study, the database of these patients was organized according to the types of documented facial analysis. The information from the morphological analysis was obtained from the records made by a Speech Therapist, with the presence of students of the Speech Therapy and Dentistry courses. To obtain the orofacial measurements, at the time, the craniofacial points were palpated, and these were marked on the skin with a dermographic pencil, using the tips of a digital caliper, without pressing against the skin surface. All measurements were performed twice, and the result obtained by the average, in millimeters ( $\mathrm{mm})$, considering both collections. The children were sitting in a chair with their feet flat on the floor, head in a natural position, teeth in occlusion, and lips sealed.

Facial analysis was recorded from the following anthropometric measurements: facial height-distance from Glabela to Gnátio (G$\mathrm{Gn}$ ); middle third of face-distance from Glabela to Subnasal (G-Sn); lower third of face: distance from Subnasal to Gnátio (Sn-Gn); right side: distance from the outer corner of the right eye to the right lip commissure (Ex-Ch); left side: distance from the outer corner of the left eye to the left lip commissure (Ex-Ch); upper lip height: distance from the subnasal to the lowest point of the upper lip (Sn-Sto); Lower lip height: Distance from the highest point of the lower lip to the gnathius (sto-gn). For the facial width, the distance between the prominence of the zygomatic arches (Zy-Zy) was considered [12].

Data on computerized facial analysis measurements were obtained from images of standardized frontal and lateral children and added to the project database between 2018 and 2019 . These included information about horizontal symmetry (median sagittal plane), the size and proportion of the facial thirds (vertical symmetry), projection of the maxilla and mandible, maxillomandibular relationship (facial profile type), as well as the evaluation of the nose (nasal projection), lips (lip length) and chin [13].

The facial type was obtained through Ricketts cephalometric analysis data, from the VERT index. E The VERT index value was obtained by means of the arithmetic mean of the five facial classification values: facial axis angle, facial depth, mandibular plane angle, lower facial height; mandibular arch, being considered brachyfacial type, children with a record above 0.5 , mesofacial between -0.5 and +0.5 and dolichofacial below -0.5) [14]. Anteroposterior (Class I, Class II division 1, Class II division 2, and Angle Class III) malocclusions and anterior crossbite, transverse (unilateral or bilateral posterior crossbite) and vertical (open bite) malocclusions were also performed. and deep overbite) [15].

There was respect for the universal principles governing bioethics and human rights in research, with prior approval of the project by the Federal University of Pernambuco Research Ethics Committee, under protocol number 77741417.0.0000.5208.

In the data analysis, measures of central tendency, dispersion measures and Pearson's Chi-square and Fisher's exact tests were obtained. In addition to the comparison test between means. The margin of error used in statistical test decisions was 5\%. Data were entered into the EXCEL spreadsheet and the statistical program used to obtain the statistical calculations was the SPSS (Statistical Package for the Social Sciences) in version 23. All children, whose data were included in this study, received dental and speech therapy assistance in the public sphere.

\section{Results}

These were described as text, with data obtained in the statistical treatment previously considered. The research sample involved information from the database of 103 male and female child patients, most of them male 59 (57.3\%) and with a mean age of $7 \pm 0.9$ years. Considering facial types and male gender, 
$22(21.4 \%)$ children were classified as mesofacial, $20(19.4 \%)$ as dolichofacial and $17(16.5 \%)$ as brachyfacial. For females, 25 (24.2\%) were brachyfacial, 12 (11.7\%) as mesofacial and 7 (6.8\%) as dolichofacial. There was a significant difference between facial types according to gender $(\mathrm{p}<0.05)$.

Also regarding facial analysis, the means of orofacial anthropometric measurements and their standard deviations were, respectively: facial height (113.42 \pm 13.54$)$, middle third (56.12 \pm 5.33$)$, lower third $(60,04 \pm 6.21)$, right side $(60$, $09 \pm 6.97$ ), left side (59.98 \pm 6.23$)$, upper lip (19.83 \pm 2.01$)$, lower lip (39.16 \pm 4.89$)$ and facial width $(124.13 \pm 8.92)$.

It is noteworthy that, when comparing males and females, there was a significant difference $(\mathrm{p}<0.05)$ between the measurements of the lower third of the face, particularly in the dolichofacial type (upper mean for males) and in facial width. especially in the brachyfacial type, (higher average for females). No significant differences were found for the other measures adopted.

Regarding the computerized analysis of the digitized images, it was found, as to the proportion between the facial sides, an asymmetry considered "normal", with minimal differences in millimeters between the right and left sides, as well as the proportion between the facial thirds in front standard. In the latter, male children had higher mean measurements in relation to the lower third of the face. The most frequent maxillomandibular relationship was class I, the most frequent type was brachyfacial and the "normal" facial profile, with a tendency to class I (straight profile).

Regarding malocclusions and according to the Angle Classification, Class I malocclusion occurred in 42 (40.8\%) records, followed by Class II (1st division) with 27 (26.2\%), Class III with 21 (20.4\%) and Class II (2nd division) with 13 (12.6\%). Regarding the other classifications of malocclusions, unilateral posterior crossbite was the most frequent 30 (29.1\%), followed by anterior open bite 28 (27.2\%), and anterior crossbite 19 (18.4\%), bilateral posterior crossbite $11(10.7 \%)$, exaggerated overbite $8(7.8 \%)$ and anterior dental crowding in the upper, lower arch or both with 7 mentions $(6.8 \%)$.

There was a significant difference between genders $(\mathrm{p}<0.05)$ for dolichofacial type and class II malocclusion (together or grouped the two divisions); these were more frequent in males, which presented even higher values for the lower third of the face.

\section{Discussion}

Due to the scarce data regarding facial analysis of infants in the literature, the present research is relevant, since facial soft tissue analysis is an indispensable evaluation method for early diagnosis, planning, execution and prognosis of problems. orthodontics in the population [16]. One of the limitations of the present study is the population and the small number of the sample; data from only 103 children were included, all attended at the university-school clinic. There was also no comparison with children in the same age group and without the presence of malocclusions. In addition, measurement accuracy can still be considered when compared to other more accurate measurement methods.

When considering facial analysis, more studies directed to the Brazilian population, which has the characteristic of miscegenation of races, should be considered. And the race is associated with the facial type. Identifying the pattern of "normality" or the characteristics often observed in children with malocclusions facilitates not only the planning of dental treatment with resources from Orthodontics and Functional Orthopedics of the Jaws, but also from other health specialties such as speech therapy, physiotherapy. and medicine. There is a better possibility of adapting facial and dental aesthetics to a functional occlusion $[17,18]$.

In this study, facial types and their frequencies were evaluated according to gender. The mesofacial type was more frequent in male children, while in females the most frequent facial type was brachyfacial. From the literature consulted, some studies have shown different results and others similar. According to Siécola et al. [6], type I and II face pattern (straight profile with increased facial convexity) were the most observed in children, with the short face being the least observed. It is noteworthy that individuals with facial pattern I have a harmonious facial growth in the sagittal and vertical direction, good jaw-to-jaw ratio, and proportionality between facial thirds; This is usually seen in the mesofacial type. This pattern shows as peculiarities: facial symmetry, good zygomatic projection, pleasant nasolabial angle, passive lip sealing or discrete interlabial space, well-defined chin-neckline and angle. The same authors did not make comparisons between the genders. There was agreement between the results obtained in the present study and the research by Berwig et al. [12], who also used anthropometry as an evaluation method. Bigliazzi et al. [19] did not find a significant difference regarding the lower third of the face when compared to the mesofacial and brachyfacial types.

Anthropometric evaluation has some advantages when compared to other methods due to its low cost, simplicity and not exposing the patient to any type of radiation. However, the accuracy of this method for facial type determination has been questioned, especially regarding the higher probability of correctness for some facial types and gender dependence. Thus, cephalometric evaluation is considered more accurate, despite the possible agreement between the methods [4,20].

It is noteworthy that one of the factors that may alter the prevalence of facial types in children with primary or mixed dentition is the breathing mode. In mouth breathing children there is a tendency to dolichofacial type in both females and males [20]. Individuals with Angle Class III tend to have a reduction in the height of the lower third of the face [21]. Changes in height measurements of the lower third of the face are not only related to the individual's facial type. Obstructive sleep apnea syndrome (OSAS) [21,22], the key to occlusion between the first permanent molars and even the stage of dental development is related to such measures $[23,24]$.

A risk factor for malocclusions in the mixed dentition is established by the presence of occlusal changes in the deciduous 
denture. Children with anterior open bite in the primary dentition have a 3.1 times greater risk of maintaining this change in the mixed dentition. Those with posterior crossbite in the primary dentition are 7.5 times more likely to maintain this malocclusion in the mixed dentition [25]. The research by Góis et al. [26] evaluated the incidence of malocclusions in 220 Brazilian children and the results found are different from those obtained in the present research. These authors found a higher prevalence of dental crowding, while posterior crossbite and anterior open bite represented the most frequent types of malocclusions in the present study.

Regarding the Angle classification, the results are in agreement with those of the study by Alhammadi [27], where Class I malocclusion was the most frequent in children with mixed dentures. According to this author, Class I affects $72.74 \%$ of the population, followed by Class II, which reaches $23.11 \%$ and, finally, Class III, which has the lowest prevalence worldwide, affecting $3.98 \%$ of children.

The development of research evaluating facial features and the prevalence of occlusal changes in children, either at regional or national level, should be encouraged. This is due to information gaps in the literature and the importance of early diagnosis of changes that may contribute negatively to the growth and development of individuals at this stage of life.

\section{Conclusion}

The most frequent facial type and malocclusions were brachyfacial, Angle Class I and posterior unilateral crossbite, respectively. Facial width measurements were higher for female children with brachyfacial type and lower third of upper face for males with dolichofacial type. Facial width measurements were higher for female children with brachyfacial type and lower third of upper face for males with dolichofacial type. Dolichofacial type, Class II malocclusion, and greater lower third of the face height are significantly more frequent in males.

\section{References}

1. Mendoza Corbetto MA (2004) Facial analysis in orthodontics. Kiru 1: 48-50.

2. Proffit WR, Fields HW, Sarver DM (2013) Contemporary orthodontics. Rio de Janeiro: Elsevier, ( ${ }^{\text {th }}$ edn), Netherlands, pp. 2-18.

3. Aksakalli S, Demir A (2014) Facial soft tissue changes after orthodontic treatment. Niger J Clin Pract 17(3): 282-286.

4. Ramires RR, Ferreira LP, Marchesan IQ, Cattoni DM, Silva MAA (2011) Proposal for facial type determination based on anthropometry. J Soc Bras Fonoaudiol 23(3): 195-200.

5. Jeelani W, Fida M, Shaikh A (2016) Facial soft tissue analysis among various vertical facial patterns. J Ayub Med Coll Abbottabad 28(1): 2934.

6. Siécola GS, Capelozza FL, Lorenzoni DC, Janson G, Henriques JFC (2017) Subjective facial analysis and its correlation with dental relationships. Dental Press J Orthod 22(2): 87-94.

7. Karimi K, Devcic Z, Popenko N, Oyoyo U, Wong BJ (2015) Morphometric facial analysis: a methodology to create lateral facial images. Oral Maxillofac Surg 19(4): 403-410.

8. Ozzeybek Can FS, Turkkahraman H (2019) Effects of rapid maxillary expansion and facemask therapy on the soft tissue profiles of Class III patients at diferente growth stages. Eur J Dent 13(2): 143-149.
9. Chang HP, Kinoshita Z, Kawamoto T (1992) Craniofacial pattern of class III deciduous dentition. Angle Orthod 62(2): 139-144.

10. Liu Y, Wang S, Wang C, Liu C (2018) Relationships of vertical facial pattern, natural head position and craniocervical posture in young Chinese children. Cranio 36(5): 311-317.

11. Silva Filho OG, Queiroz APC, Herkrath J, Silva GFB (2008) Correlation between facial pattern and sagittal relationship between dental arches in deciduous dentition: epidemiological considerations. R Dental Press Ortodont Ortop Facial 13(1): 101-112.

12. Berwig LC, Fiqueiredo FSP, Bolsan GP, Milanesi JM, Marquezan M, et al. (2017) Anthropometric orofacial measurements of children according to facial type. Rev CEFAC 19(1): 63-68.

13. Moreira Júnior R, Ribeiro PD, Condezo AFB, Cini MA, De Antoni CC, et al. (2018) Oral health fundamentals of facial analysis for aesthetic harmonization in Brazilian dentistry. Clipe Odonto 9: 59-65.

14. Bae EJ, Kwon HJ, Kwoon OW (2014) Changes in longitudinal craniofacial growth in subjects with normal occlusions using the Ricketts analysis. Korean J Orthod 44(2): 77-87.

15. Bittencourt MA, Machado AW (2010) An overview of the prevalence of malocclusion in 6 to 10-year-old children in Brazil. Dental Press J Orthod 15(6): 113-122.

16. Thiesen G (2006) The role of facial analysis in contemporary orthodontics. Rev Assoc Paul Cir Dent 60(5): 380-385.

17. Cattoni DM, Fernandes FDM (2009) Anthropometric orofacial measurements of children from Sao Paulo and from North America: comparative study. Pro Fono 21(1): 25-29.

18. Amirav I, Masumbuko CK, Hawkes MT, Solomon I, Aldar Y, et al. (2019) 3D analysis of child facial dimensions for design of medical devices in low-middle income countries (LMIC). PloS ONE 14(5): 1-12.

19. Bigliazzi R, Walverde EA, Oliveira DTN, Bertoz APM, Junior KF (2017) Morphometric analysis of three normal facial types in mixed dentition using posteroanterior cephalometric radiographs: preliminary results. Acta Scientiarum Health Sciences 39(2): 227-232.

20. Nastri VHT, Bommarito S (2007) Breath evaluation based on different facial types in patients with malocclusion. Revista Odonto 15(30): 97106.

21. Bolzan GP, Berwig LC, Prade LS, Weinmann ARM, Moraes AB, et al. (2014) Agreement between Anthropometry and cephalometry methods in classification of the facial type. Rev CEFAC 16(1): 222-227.

22. Yap B, Kontos A, Pamula Y, et al. (2019) Differences in dentofacial morphology in children with sleep disordered breathing are detected with routine orthodontics records. Sleep Med 55: 109-114.

23. Mouakeh M (2000) Cephalometric evaluation of craniofacial pattern of Syrian children with Class III malocclusion. Am J Orthod Dentofacial Orthop 119(6): 640-649.

24. Dimaggio FR, Ciusa V, Sforza C, Ferrario VF (2007) Photographic softtissue profile analysis in children ant 6 years of age. American Journal of Orthodontics and Dentiofacial Orthopedics 132(4): 475-480.

25. Vucic S, Dhamo B, Jaddoe VWV, Wolvius EB, Ongkosuwito EM (2019) Dental development and craniofacial morphology in school-age children. American Journal of Orthodontics and Dentofacial Orthopedics 156(2): 229-237.

26. Góis EG, Vale MP, Paiva SM, Abreu MH, Serra-Negra JM, et al. (2012) Incidence of malocclusion between primary and mixed dentitions among Brazilian children: A 5-year longitudinal study. Angle Orthodontistt 82(3): 495-500.

27. Alhammadi SM, Halboub E, Fayed MS, Labib A, El-Saaidi C (2018) Global distribution of malocclusion traits: A systematic review. Dental Press J Orthod 23(6): 1-10. 


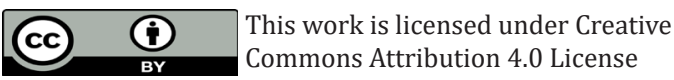

To Submit Your Article Click Here: Submit Article

DOI: 10.32474/MADOHC.2020.04.000184

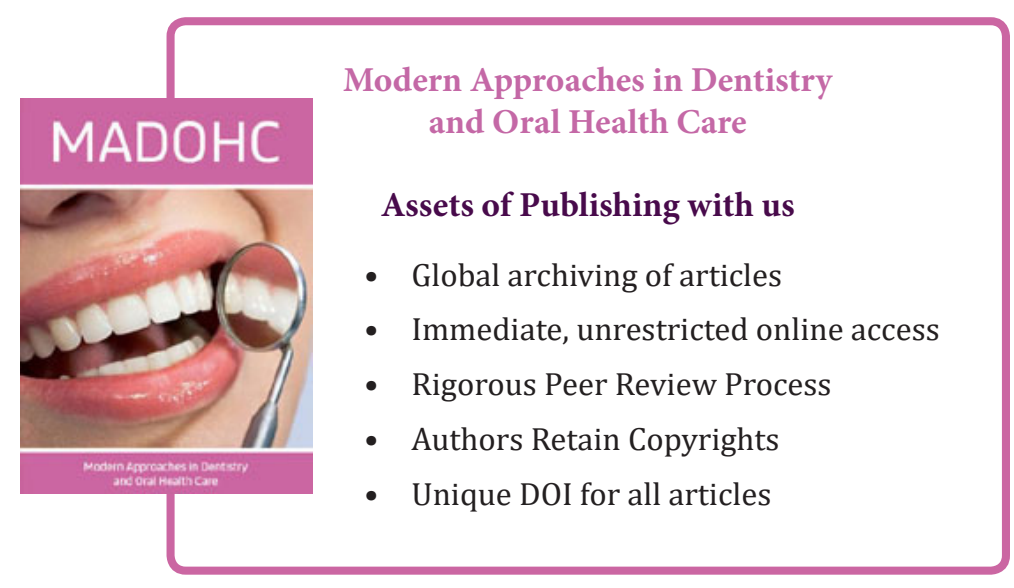

